\title{
Sodium channel point mutations associated with pyrethroid resistance in Chinese strains of Culex pipiens quinquefasciatus (Diptera: Culicidae)
}

\author{
Minghui Zhao ${ }^{1,2}$, Yande Dong ${ }^{1,2}$, Xin Ran ${ }^{1}$, Xiaoxia Guo ${ }^{1}$, Dan Xing ${ }^{1}$, Yingmei Zhang ${ }^{1}$, Ting Yan ${ }^{1}$, Xiaojuan Zhu',
} Jianxin Su', Hengduan Zhang ${ }^{1}$, Gang Wang ${ }^{1}$, Wenjun Hou' ${ }^{1}$ Zhiming $\mathrm{Wu}^{1}$, Chunxiao Li ${ }^{i^{*}}$ and Tongyan Zhao ${ }^{1 *}$

\begin{abstract}
Background: Pesticide resistance due to sodium channel point mutations has been well documented in many mosquito species.

Methods: We tested the resistance of six, wild, Chinese populations of the mosquito Culex pipiens quinquefasciatus to deltamethrin and cyhalothrin. The full length of the sodium channel gene was cloned and sequenced from a pooled sample of mosquitoes from each population.

Results: Seven amino acid alterations were found (V250M, R436K, M943V, 1973T, L1035F, L1035S and E1901D). Correlation between the frequencies of these mutations and the level of pesticide resistance $\left(L C_{50}\right)$ associated with them indicates that those at position L1035 (corresponding to position L1014F in the house fly, Musca domestica; GenBank Accession No: X96668) are associated with resistance to deltamethrin and cyhalothrin. The frequency of the L1035F mutation was significantly correlated with resistance to deltamethrin $\left(R^{2}=0.536, P=0.049\right)$ and cyhalothrin $\left(R^{2}=0.626, P=0.030\right)$, and the combined frequency of the L1035F and L1035S mutations was significantly correlated with resistance to both deltamethrin $\left(R^{2}=0.661, P=0.025\right)$, and cyhalothrin $\left(R^{2}=0.803, P=0.008\right)$. None of the other mutations were correlated with either deltamethrin or cyhalothrin resistance. Interestingly, an HWE test indicated significant linkage between the M943V and 1973T mutations $(P<0.01)$, but further research is required to determine the biological significance of this linkage.
\end{abstract}

Conclusions: Identifying these mutations may be of practical benefit to the development of pesticide resistance management programs.

\section{Background}

Cx. pipiens quinquefasciatus is the predominant mosquito species in urban environments in southern China. This species is a major biting nuisance, particularly in urban areas where it thrives in wet pit-latrines, polluted puddles, gutters, and blocked open drains. It is also a major vector of filariasis [1], West Nile virus (WNV) [2], St. Louis encephalitis virus (SLEV) [3], and Rift Valley Fever virus (RVFV) [4,5]. Cx. p. quinquefasciatus is one of the most studied mosquito species with respect to insecticide resistance.

\footnotetext{
*Correspondence: aedes@126.com; tongyanzhao@126.com 1 Beijing Institute of Microbiology and Epidemiology, State Key Laboratory of Pathogen and Biosecurity, Beijing, China

Full list of author information is available at the end of the article
}

"Pyrethroid" is the general term for a group of synthetic chemicals based on the structure of natural pyrethrins derived from Chrysanthemum flowers [6]. Pyrethroids are now becoming the most commonly used insecticides for mosquito control [7]. Compared to other insecticides, most pyrethroids are nontoxic to mammals but have a high knockdown effect on insects. Unfortunately, the extensive use of pyrethroids has led to the widespread development of resistance to this group of pesticides in mosquito populations [8-10]. The increase in resistance can be both large and rapid; one study reported an approximately 298 -fold increase in resistance in $C x . p$. quinquefasciatus after 10 generations of exposure to deltamethrin [11].

Modification of the active site of the sodium channel is an important mechanism involved in pyrethroid resistance $[12,13]$. Voltage-gated sodium channels are integral 


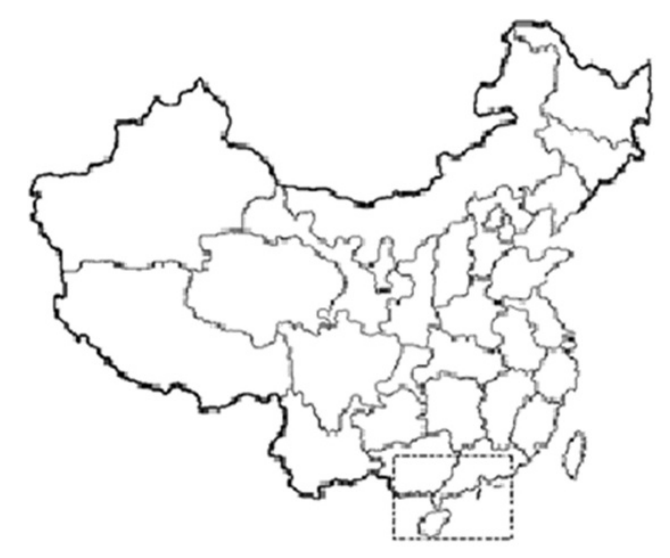

(1)- ZJ strain---36 RR-- $28.8 \%$

(2)- PX strain- $428 \mathrm{RR}--54.0 \%$

(3)- CL strain----9 RR-- $56.3 \%$

(4)- BA strain-186 RR-- $51.6 \%$

(5)- LS strain- 312 RR-- $65.4 \%$

(b)- $\mathrm{FH}$ strain-1019RR-- $74.3 \%$

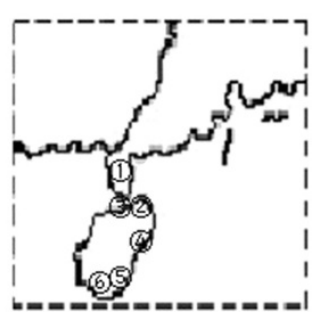

Figure 1 The distribution of collecting sites of $\mathbf{C x}$. p. quinquefasciatus. (1)-(6) indicated the six field strains of $C x$. $p$. quinquefasciatus in China. RR was resistance ratio to deltamethrin, and the percentages were mutation frequencies of L1035F.

transmembrane proteins responsible for the rapidly rising phase of action potentials that is critical for electrical signaling in most excitable cells. Because of their crucial role in membrane excitability, sodium channels are the target of a great variety of neurotoxins, including insecticidal pyrethrins [14]. Pyrethroid insecticides bind to insect para-sodium channels locking them in an open state thereby disrupting neuronal signaling resulting in paralysis and death.

Point mutations in the para-sodium channel gene that make sodium channel insensitive to pyrethrins are an important mechanism of resistance to pyrethroid insecticides in various insect species [15-22]. The most common mutation is the substitution of leucine by phenylalanine at residue L1014, commonly referred to as the kdr (knockdown resistance) mutation. Resistance conferred by the L1014F mutation was first described in the Italian housefly with respect to DDT [23] and subsequently named knockdown resistance [24]. Variants of this mutation such as L1014S, L1014H, L1014W and L1014C have also been reported [25-28]. Another mutation, M918T, has also been found in many insects [29-31]. This mutation and the L1014F mutation often occur together in which case they confer what has been called "super-kdr resistance".

One approach to investigating pesticide resistance in mosquitoes is to first identify mutations that could potentially confer resistance and then attempt to correlate the frequency of these with actual pesticide resistance. Through a combination of insecticide bioassays and molecular techniques, we identified mutations associated with resistance to deltamethrin and cyhalothrin in six wild Chinese populations of $C x$. p. quinquefasciatus and assessed the similarity between these and previously documented mutations in the sodium channel gene. Knowledge of these mutations may have practical benefits for further research on pesticide resistance in mosquitoes and for designing resistance management programs.

\section{Methods \\ Mosquito strains}

Cx. p. quinquefasciatus larvae and some female adults were collected from six different field locations: Haikou Poxiang (E110'19'33.79", N1959'55.07"), Haikou Changliu

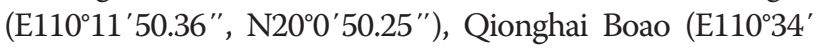
57.13", N19 $09^{\prime} 42.07^{\prime \prime}$ ) and Sanya Fenghuang (E109 $26^{\prime}$ 54.38", N18 $\left.{ }^{\circ} 18^{\prime} 2.91^{\prime \prime}\right)$ in 2012; Guangdong Zhanjiang (E110 $\left.23^{\prime} 53.05^{\prime \prime}, \mathrm{N} 21^{\circ} 11^{\prime} 30.19^{\prime \prime}\right)$ and Hainan Lingshui (E110 $\left.2^{\prime} 15.01^{\prime \prime}, \mathrm{N} 18^{\circ} 30^{\prime} 21.77^{\prime \prime}\right)$ in 2013 (Figure 1). Larvae were reared to adulthood in captivity but the wild caught female adults were frozen in liquid nitrogen for subsequent genetic testing. The control population for insecticide bioassays was a laboratory strain that had not been exposed to insecticides for more than 10 years.

\section{Bioassay}

Bioassays were conducted by putting thirty late 3rd or early 4th instar larvae into pans containing $199 \mathrm{ml}$ water and $1 \mathrm{ml}$ of either deltamethrin or cyhalothrin. The insecticides were added to each pan using an automatic pipette according to the methods specified by the WHO [32]. Larval

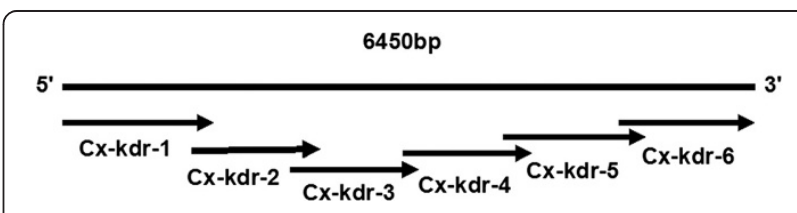

Figure 2 Schematic diagram of amplification of the sodium channel gene of $C x$. p. quinquefasciatus. The complete gene sequence was $6450 \mathrm{bp}$, and the gene's six sections are indicated by arrows. 
Table 1 The four pairs of specific primers used to amplify sodium channel gene mutations detected in Cx. p. quinquefasciatus

\begin{tabular}{llc}
\hline Primers & $\mathbf{5}^{\prime} \rightarrow \mathbf{3}^{\prime}$ Sequence & length (bp) \\
\hline CX-M1 & GATGATCATGCCATCCACGC & 548 \\
& CTTCCTCACATTGGCCAGCA & \\
CX-M2 & CGACAGTCGAATCTACCGAGGTG & 995 \\
& CTTCTCCTTGTTGTTGCGTCG & \\
CX-M3 & GAGCTGTTCATCACGCTCTG & 689 \\
& GCCGACAAACTCGAGGAACC & \\
CX-M4 & GCCGGATAACGACAAGGGTT & 661 \\
\hline
\end{tabular}

mortality was recorded $24 \mathrm{~h}$ after each treatment. No food was offered to the larvae during bioassays. Larvae were kept in a laboratory under the following conditions: $14 \mathrm{~L}: 10 \mathrm{D}$ photoperiod, $75 \%$ relative humidity and a temperature of $26 \pm 1^{\circ} \mathrm{C}$ during bioassays. Bioassays of each insecticide were repeated three times. Statistical analyses were performed using SPSS software version 13.

\section{Extraction of RNA, CDNA synthesis and PCR amplification}

Total RNA was extracted from mosquitoes from each population with Trizol reagent (GBT) following the manufacturer's protocol and cDNA was synthesized from the extracted total RNA with a cDNA synthesis kit (Transgen Biotech). The synthesized cDNA was stored at $-20^{\circ} \mathrm{C}$. Gene-specific primers from Zhao et al. (2014) used to amplify the sodium channel gene of specimens from each population [33]. The sodium channel gene is $6450 \mathrm{bp}$ and is divided into six sections (Figure 2).

\section{Cloning and sequencing of PCR products}

To identify mutations in the sodium channel gene, the cDNA of a pooled sample of $C x . p$. quinquefasciatus comprised of specimens from each of the six populations was cloned and sequenced. PCR products were purified using a universal DNA purification kit (TIANGEN) and the purified products were ligated into the pEASY-T1 vector (TRANSGEN). The recombinant plasmids were then cloned into Trans1-T1 competent cells (TRANSGEN). The microbials were spread on LB solid medium (including ampicillin, X-gal, IPTG) and cultured overnight. White clones were selected, placed in LB liquid medium and cultured to turbidity. Positive clones were identified by PCR using M13 forward and reverse primers and sequenced by Tianyi Biotech [34]. Based on the discovery of clones, the allele frequency of each mutation was determined by specific PCR amplification and sequencing of the mutations found in each population. In this procedure, a single mosquito's RNA was extracted and reverse transcribed to cDNA, then amplified by specific PCR before being sequenced. The gene-specific primers used to amplify the mutations in the $C x . p$. quinquefasciatus para-sodium channel gene were designed in NCBI Primer BLAST (Table 1).

\section{Analysis of genetic linkage between mutations}

We use the GENEPOP software package to estimate conformity to the HWE and genetic linkage between mutations.

Table 2 Levels of deltamethrin and cyhalothrin resistance measured in $C x$. p. quinquefasciatus

\begin{tabular}{|c|c|c|c|c|c|c|}
\hline Population & Insecticide & $\mathrm{LC}_{50}(\mathrm{ppm})(95 \% \mathrm{CL})^{1}$ & Regression Equation & $x^{2}$ & $P$-value & $\mathrm{RR}^{2}$ \\
\hline \multirow[t]{2}{*}{ LA } & deltamethrin & $0.001(0.001,0.001)$ & $Y=7.412+2.371 x$ & 29.78 & 0.019 & 1 \\
\hline & cyhalothrin & $0.001(0.001,0.001)$ & $Y=6.819+2.356 x$ & 16.76 & 0.606 & 1 \\
\hline \multirow[t]{2}{*}{$\mathrm{CL}$} & deltamethrin & $0.009(0.006,0.011)$ & $Y=3.028+1.475 x$ & 13.34 & 0.648 & 9 \\
\hline & cyhalothrin & $0.014(0.010,0.017)$ & $Y=2.898+1.551 x$ & 10.63 & 0.832 & 14 \\
\hline \multirow[t]{2}{*}{ PX } & deltamethrin & $0.428(0.385,0.476)$ & $Y=0.842+2.284 x$ & 31.44 & 0.175 & 428 \\
\hline & cyhalothrin & $0.396(0.332,0.468)$ & $Y=0.610+1.517 x$ & 24.84 & 0.305 & 396 \\
\hline \multirow[t]{2}{*}{ BA } & deltamethrin & $0.186(0.151,0.231)$ & $Y=1.314+1.799 x$ & 23.34 & 0.105 & 186 \\
\hline & cyhalothrin & $0.215(0.172,0.264)$ & $Y=0.761+1.139 x$ & 23.28 & 0.386 & 215 \\
\hline \multirow[t]{2}{*}{$\mathrm{FH}$} & deltamethrin & $1.019(0.811,1.268)$ & $Y=-0.012+1.439 x$ & 32.20 & 0.075 & 1019 \\
\hline & cyhalothrin & $1.291(1.051,1.560)$ & $Y=-0.165+1.484 x$ & 16.83 & 0.396 & 1291 \\
\hline \multirow[t]{2}{*}{ ZJ } & deltamethrin & $0.036(0.031,0.041)$ & $Y=3.073+2.127 x$ & 18.05 & 0.703 & 36 \\
\hline & cyhalothrin & $0.042(0.037,0.048)$ & $Y=3.048+2.215 x$ & 26.82 & 0.218 & 42 \\
\hline \multirow[t]{2}{*}{ LS } & deltamethrin & $0.312(0.234,0.413)$ & $Y=0.630+0.541 x$ & 40.04 & 0.011 & 312 \\
\hline & cyhalothrin & $0.641(0.520,0.800)$ & $Y=0.221+0.497 x$ & 25.05 & 0.295 & 641 \\
\hline
\end{tabular}

( $\mathrm{LA}=$ Lab strain; $\mathrm{CL}=$ Haikou Changliu; PX = Haikou Poxiang; BA = Qionghai Boao; FH = Sanya Fenghuang; ZJ = Guangdong Zhanjiang; LS = Hainan Lingshui.

${ }^{1} \mathrm{CL}=$ confidence limits, ${ }^{2} \mathrm{RR}=$ Resistance Ratio). 


\section{MTEDLDSISEEERSLFRPFTRESLIVIEERIANEQAKQREIEKKRAEGETGFGRKKKKKE} MTEDLDSISEEERSLFRPFTRESLIVIEERIANEQARQRELEKKRAEGE......... IRYDDEDEDEGPOPDSTLEOGVPI PVRMOGSEPPELASTPLEDTDAFYSNTKTFVYVSKG IRYDDEDEDEGPQPDSTLEQGVPIPVRMQGSFPPELASTPLEDIDAFYSNIKIFVVVSKG KDIFRFSATNALYVLDPFNPIRRVAIYILVHPLFSFFIITTILGNCILMTMPSTPTVEST KDIFRFSATNALYVLDPFNPIRRVAIYILVHPLFSFFIITTILGNCILMTMPSTPTVEST EVIFTGIYTFESAVKVMARGFILQPFTYLRDAWNWLDFVVIALAYVTMGIDLGNLAALRT .................................. YVTMGIDLGNLAALRT FRVLRALKTVAIVPGLKTIVGAVIESVKNLRDVIILTMFSLSVFALMGLQIYMGVLTOKC FRVLRALKTVAIVPGLKTIVGAVIESVKNLRDVIILTMFSLSVFALMGLQIYMGVLTOKC IKEFPTDGSWGNLTHENWERHHSNDSNWYFSETGDTPLCGNSSGAGQCEEGYVCLQGFGD IKEFPTDGSWGNLTHENWERHHSNDSNWYFSETGDTPLCGNSSGAGQCEEGYVCLQGFGD NPNYGYTSFDTFGWAFLSAFRLMTODYWENLYOLVLRSAGPWHMLFFTVIIFLGSFYLVN NPNYGYTSFDTFGWAFLSAFRLMTQDYWENL YQLVLRSAGPWHMLFFIVIIFLGSFYLVN

LILAIVAMSYDELQKRAEEEEAAEEEALREAEEAAAAKQAKLEAHAAAAAAAANPEIAKS LILAIVAMSYDELQKRAEEEEAAEEEALREAEEAAAAKQAKLEAHAAAAAAAANPEIAKS PSDFSCHSYELFVGQEKGNDDNNKEKMSIRSEGLESVSEITRTTAPTATAAGTAKARKVS PSDFSCHSYELFVGQEKGNDDNNKEKMSIRSEGLES. $\ldots \ldots \ldots \ldots \ldots \ldots \ldots$ AGVAAAFQKASLSLPGSPFNLRRGSRGSHQFTIRNGRGRFVGVPGSDRKPLVLSTYLDAQ . EHLPYADDSNAVT PMSEENGAITVPVYYANLGSRHSSYTSHOSRISYTSHGDLLGGMTKE EHLPYADDSNAVTPMSEENGAIIVPVYYANLGSRHSSYTSHQSRISYTSHGDLLGGMTKE EHLPYADDSNAVT PMSEENGAIIVPVYYANLGSRHSSYTSHOSRISYTSHGDLIGGMTKE EHLPYADDSNAVTPMSEENGAITVPVYYANLGSRHSSYTSHOSRISYTSHGDLLGGMTKE SRLRSRTORNTNHSIVPPANMAASAASVTGAGSGAPNMSYVDTNHKGQQRDFDQSODYTD SRLRSRTORNTNHSTVPPANMAASAASVTGAGSGAPNMSYVDTNHKGOORDFDOSODYTD DAGKIKHNDNPFIEPSOTOTVVDMKDVMVLNDIIEOAAGRHSRASDHGVSVYYFPTEDDD DAGKIKHNDNPFIEPSQTOTVVDMKDVMVLNDI IEQAAGRHSRASDHG .......EDDD EDGPTFKDKAVEFGMRMIDIFCVWDCCWVWLKFOEWVSFTVEDPFVELFITLCTVVNTLE EDGPTFKDKAVEFGMRMIDIFCVWDCCWVWLKFQEWVSFIVFDPFVELFITLCIVVNTLF

MALDHHDMNPDMERALKSGNYFFTATFAIEATMKLIAMSPKWYFQEGWNIFDFITVALSI MALDHHDMNPDMERALKSGNYFFTATFAIEATMKLIAMSPKWYFOEGWNIFDFITVALSL LELGLEGVOGLSVLRSFRLLRVFKLAKSWPTLNLLISTMGRTMGALGNLTFVLCIIIFI 4 LELGLEGVQGLSVLRSFRLLRVFKLAKSWPTLNLIISIMGRTMGALGNLTFVLCIIIFIF 1 AVMGMOLFGKNYIDNVDRFPDKDLPRWNFTDFMHSFMIVFRVLCGEWIESMKDCMLVGDV AVMGMOLFGKNYIDNVDRFPDKDLPRWNFTDFMHSFMTVFRVLCGEWIESMWDCMLVGDV 021 SCIPFFLATVVI GNLVVLNLFLALLLSNFGSSSLSAPTADNETNKIAEAFNRISRFSNW I 904 SCIPFFLATVVIGNLVVLNLFLALLLSNFGSSSLSAPTADNETNKIAEAFNRISRFSNWI 081 KANIAAALKFVKNKLTSOTASVQPAGEOHNHLSWIWSEGKGVCPCISAEHGENEIEITPD 964 KANTAAALKFVKNKLTSQTASVQPA $\ldots \ldots \ldots \ldots \ldots \ldots \ldots \ldots \ldots \ldots$ 1141 DILADGLLKKKGVKEHNQLEVAIGDGMEFTIHGDLKNKGKKNKQLMNNSKVI GNSISNHQD 990 DILADGLLKKGVKEHNQLEVAIGDGMEFTIHGDLKNKGKKNKQLMNNSK......... 1201 NKIEHELNHRGMSTODDDTASTKSYGSHKNRPEKDESHKGSAETLEGEEKG $1038 \ldots \ldots \ldots \ldots \ldots$ DDTASIKSYGSHKNRPFKDESHKGSAETLEGEEKRDASKEDLG 1261 DEELDDECEGEEGPLDGEMIIHAEEDEVIEDAPADCFPDNCYKRFPALAGDDDAPFWOGW 1083 DEELDDECEGEEGPLDGEMI IHAEEDEVIEDAPADCFPDNCYKRFPALAGDDDAPFWOGW

1321 GNLRLKTFQLIENKYFETAVITMILLSSLALALEDVHLPHRPILQDVLYYMDRIFTVIFF 1143 GNLRLKTFQLIENKYFETAVITMILLSSLALALEDVHLPHRPILQDVLYYMDRIFTVIFF 1381 LEMLIKWLALGFRVYFTNAWCWLDFITVMVSL INFVASLCGAGGIOAFKTMRTLRALRPI

1203 LEMLIKWLALGFRVYFTNAWCWLDFI IVMVSLINFVASLCGAGGIQAFKTMRTLRALRPL 1441 RAMSRMQGMRVVVNALVQAIPSI FNVLLVCL IFWLIFAIMGVQLFAGKYFKCVDTNKTTL 1263 RAMSRMOGMRVVYNALVOAIPSIFNVLLVCLIFWLIFAIMGVOLFAGKYFKCVDTNKTTI 1501 SHEIIPDVNACIAENYTWENSPMNFDHVGKAYLCLFQVATFKGWIQIMNDAIDSRDIGKQ 1323 SHEIIPDVNACIAENYTWENSPMNFDHVGKAYLCLFQVATFKGWIQIMNDAIDSRDIGKO

1561 PIRETNIYMYLYFVFFIIFGSFFTLNLFIGVIIDNFNEQKKKAGGSLEMFMTEDQKKYYN 1383 PIRETNIYMYLYFVFFIIFGSFFTLNLFIGVIIDNFNEQKKKAGGS $\ldots \ldots \ldots \ldots$ YYN 1621 AMKKMGGSKKPLKAI PRPKWRPQAIVFEICTNKKFDMI IMLFI IFNMLTMTLDHYKOTETF 1432 AMKKMGSKKPLKAIPRPKWRPQAIVFEICTNKKFDMI IMLFIGFNML TMTLDHYKQTETF 1681 SAVLDYLNMIFICIFSSECLMKTFALRYHYFIEPWNLFDFVVVILSILGLVLSDITEKYE 1492 SAVLDYLMMIFICIFSSECLMKIFALRYHYFIEPWNLFDFVVVILSILGLVLSDLIEKYF 1741 VSPTLLRVVRVAKVGRVLRLVKGAKGIRTLLFALAMSLPALFNICLLLFLVMFIFAIFGM 1552 VSPTLLRVVRVAKVGRVLRLVKGAKGIRTLLFALAMSLPALFNICLLLFLVMFIFAIFGM 1801 SFFMHVKDKSGLDDVYNFKTFGQSMILLFQMSTSAGWDGVLDGI INEEDCLPPDNDKGYP 1612 SFFMHVKDKSGLDDVYNFKTFGQSMILLFQMSTSAGWDGVLDGI INEEDCLPPDNDKGYP 1861 GNCGSATIGITYLLAYLVISFLIVINMYIAVILENYSOATEDVQEGLTDDDYDMYYEIWO 1672 GNCGSATIGITYLLAYLVISFLIVINMYIAVILENYSOATEDVQEGLTDDDYDMYYEIWO 1921 QFDPDGTQYIRYDQLSDFLDVLEPPLQIHKPNKYKIISMDIPICRGDMMFCVDILDALTK 1732 QFDPDGTQYIRYDQLSDFLDVLEPPLQIHKPNKYKIISMDIPICRGDMMFCVDILDALTK 1981 DFFARKGNPIEDSAEMGEVQQRPDEVGYEPVSSTLWRQREEYCARLIQHAYRNFKERGGV 1792 DFFARKGNPIEDSAEMGEVQQRPDEVGYEPVSSTLWRQREEYCARLIQHAYRNFKERGG 2041 GGGGGGGGGGGGGGGEGAGDDTDADACDNEPGIGSPGAVSGGGGSIAGGGSQANLGPPS 1852 GGGGGGGGGGGGGGGGEGAGDDTDADACDNEPGIGSPGAVSGGGGSIAGGGSQANLGPPS 2101 PKESPDGNNDPQGRQTAVLVESDGFVTKNGHRVVIHSRSPSITSRSADV 1912 PKESPDGNNDPQGRQTAVLVESDGFVTKNGHRVVIHSRSPSITSRSADV

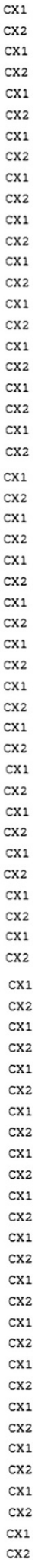

Figure 3 Alternative splicing in the sodium channel gene of $C x . p$. quinquefasciatus. $C X 1$ was the sequence of $C X . p$. quinquefasciatus (GenBank Accession No.: AB453977.1). CX2 was the sequence of $C x$. p. quinquefasciatus in China. The dots indicated the alternative splicings. In the 517-570, there were three kinds of alternative splicings (517-550, 542-550, and 542-570); In the 1106-1139, there were also three kinds of alternative splicings (1106-1118, 1106-1128, and 1106-1139).

\section{Correlation of pesticide resistance with the frequencies of different mutations}

The resistance $\left(\mathrm{LC}_{50}\right)$ of the six populations to deltamethrin and cyhalothrin was determined by bioassay and the allele frequencies of the various mutations determined by gene-specific amplification and sequencing as described above. The $\mathrm{LC}_{50}$ of a laboratory strain that had not been exposed to either pesticide was also determined to serve as a control. Correlations between resistance and mutation frequency were analyzed using Graphpad Prism 5.

\section{Results}

\section{Resistance to deltamethrin and cyhalothrin}

$\mathrm{LC}_{50}$ values of the seven different populations ranged from 0.009 to $1.019 \mathrm{ppm}$ for deltamethrin and from 0.014 to $1.291 \mathrm{ppm}$ for cyhalothrin (Table 2). The CL strain was the most susceptible to both insecticides. The FH strain was the most resistant; 1019 times more resistant to deltamethrin and 1291 times more resistant to cyhalothrin than the laboratory strain ( $\left.\mathrm{LC}_{50} 0.001 \mathrm{ppm}\right)$.

\section{Sodium channel gene mutations}

Seven mutations (V250M, R436K, M943V, I973T, L1035F, L1035S and E1901D) were identified. Because these seven mutations were identified in a pooled sample they did not necessarily occur in the same individuals. The seven mutations were V250M: GTG $\rightarrow$ ATG, R436K: AGG $\rightarrow$ AAG, M943V: ATG $\rightarrow$ GTG, I973T: ATC $\rightarrow$ ACA, L1035F: TTA $\rightarrow$ TTT, L1035S: TTA $\rightarrow$ TCA, and E1901D: GAG $\rightarrow$ GAT. In addition, eleven alternative splices in the sodium channel gene were detected (Figure 3).

\section{Genetic and genotypic frequencies}

Genetic and genotypic frequencies were showed in Table 3.

\section{Analysis of genetic linkage between mutations}

The results of HWE were showed in Tables 4. A significant $(P>0.05)$ heterozygote deficit was detected in only one (the LS) population, but there was evidence of heterozygote excess in some populations. The frequency of four mutations (R436K, M943V, I973T, and L1035F/S) significantly deviated from the HWE $(\mathrm{P}<0.01)$ across all populations.

The results of analysis of linkage disequilibrium between mutations are shown in Table 5. Significant linkage disequilibrium was found between M943V and I973T $(\mathrm{P}<0.01)$. 
Table 3 Gene and genotype frequencies of seven sodium channel gene mutations calculated in six populations of Cx. p. quinquefasciatus

\begin{tabular}{|c|c|c|c|c|c|c|}
\hline \multirow[t]{2}{*}{ Mutation } & \multirow[t]{2}{*}{ Population } & \multirow[t]{2}{*}{$\mathbf{n}$} & \multicolumn{4}{|c|}{$\begin{array}{c}\text { Genotype frequency and } \\
\text { gene frequency (\%) }\end{array}$} \\
\hline & & & $\mathrm{SS}^{1}$ & $\mathrm{RS}^{2}$ & $\mathrm{RR}^{3}$ & $\mathrm{R}^{4}$ \\
\hline \multirow[t]{6}{*}{ V250M } & $\mathrm{FH}$ & 49 & 61.2 & 34.7 & 4.10 & 21.4 \\
\hline & $P X$ & 31 & 41.9 & 48.4 & 9.70 & 33.9 \\
\hline & BA & 29 & 55.2 & 37.9 & 6.90 & 25.9 \\
\hline & ZJ & 31 & 48.4 & 51.6 & 0.00 & 25.8 \\
\hline & $\mathrm{CL}$ & 32 & 65.6 & 34.4 & 0.00 & 17.2 \\
\hline & LS & 36 & 61.1 & 27.8 & 11.1 & 25.0 \\
\hline \multirow[t]{6}{*}{ R436K } & $\mathrm{FH}$ & 27 & 7.40 & 92.6 & 0.00 & 46.3 \\
\hline & $P X$ & 12 & 0.00 & 100 & 0.00 & 50.0 \\
\hline & BA & 10 & 0.00 & 100 & 0.00 & 50.0 \\
\hline & ZJ & 20 & 0.00 & 100 & 0.00 & 50.0 \\
\hline & $\mathrm{CL}$ & 13 & 0.00 & 100 & 0.00 & 50.0 \\
\hline & LS & 15 & 6.70 & 93.3 & 0.00 & 46.7 \\
\hline \multirow[t]{6}{*}{ M943V } & $\mathrm{FH}$ & 32 & 34.4 & 65.6 & 0.00 & 32.8 \\
\hline & $P X$ & 38 & 44.7 & 55.3 & 0.00 & 27.6 \\
\hline & BA & 31 & 32.3 & 67.7 & 0.00 & 33.9 \\
\hline & ZJ & 33 & 48.5 & 51.5 & 0.00 & 25.8 \\
\hline & $\mathrm{CL}$ & 32 & 28.1 & 71.9 & 0.00 & 35.9 \\
\hline & LS & 31 & 16.1 & 83.9 & 0.00 & 41.9 \\
\hline \multirow[t]{6}{*}{$1973 T$} & $\mathrm{FH}$ & 32 & 46.9 & 53.1 & 0.00 & 26.7 \\
\hline & PX & 38 & 39.5 & 60.5 & 0.00 & 30.3 \\
\hline & BA & 31 & 29.0 & 71.0 & 0.00 & 35.5 \\
\hline & ZJ & 33 & 51.5 & 48.5 & 0.00 & 24.2 \\
\hline & $\mathrm{CL}$ & 32 & 37.5 & 62.5 & 0.00 & 31.3 \\
\hline & LS & 31 & 32.3 & 67.7 & 0.00 & 33.9 \\
\hline \multirow[t]{6}{*}{ L1035F } & $\mathrm{FH}$ & 35 & 0.00 & 11.4 & 68.6 & 74.3 \\
\hline & $P X$ & 38 & 5.26 & 18.4 & 44.7 & 54.0 \\
\hline & BA & 31 & 16.1 & 45.2 & 29.0 & 51.6 \\
\hline & ZJ & 33 & 9.09 & 45.5 & 6.06 & 28.8 \\
\hline & $\mathrm{CL}$ & 32 & 3.13 & 68.8 & 21.9 & 56.3 \\
\hline & LS & 31 & 0.00 & 12.9 & 58.1 & 64.5 \\
\hline \multirow[t]{6}{*}{ L1035S } & $\mathrm{FH}$ & 35 & 0.00 & 20.0 & 0.00 & 10.0 \\
\hline & $P X$ & 38 & 5.26 & 31.6 & 0.00 & 15.8 \\
\hline & BA & 31 & 16.1 & 9.68 & 0.00 & 4.84 \\
\hline & ZJ & 33 & 9.09 & 36.4 & 3.03 & 21.2 \\
\hline & $\mathrm{CL}$ & 32 & 3.13 & 6.25 & 0.00 & 3.13 \\
\hline & LS & 31 & 0.00 & 25.8 & 3.23 & 16.1 \\
\hline \multirow[t]{3}{*}{ E1901D } & $\mathrm{FH}$ & 32 & 34.4 & 50.0 & 15.6 & 40.6 \\
\hline & $P X$ & 31 & 38.7 & 58.1 & 3.22 & 32.3 \\
\hline & BA & 34 & 55.9 & 44.1 & 0.00 & 22.1 \\
\hline
\end{tabular}

Table 3 Gene and genotype frequencies of seven sodium channel gene mutations calculated in six populations of Cx. p. quinquefasciatus (Continued)

\begin{tabular}{llllll}
\hline ZJ & 30 & 83.3 & 16.7 & 0.00 & 8.33 \\
CL & 22 & 40.9 & 59.1 & 0.00 & 29.6 \\
LS & 38 & 34.2 & 41.1 & 23.7 & 44.7
\end{tabular}

("S" = the amino acid sequence of the sodium channel gene listed in GenBank (Accession No.: AB453977.1). "R" = mutant variants of "S". "SS" = "S"

homozygotes, "RS" = heterozygotes, and "RR" = "R" homozygotes).

${ }^{1} \mathrm{SS}$ frequency $=\mathrm{SS} \div(\mathrm{SS}+\mathrm{RS}+\mathrm{RR}) \times 100 \% ;{ }^{2} \mathrm{RS}$ frequency $=\mathrm{RS} \div(\mathrm{SS}+\mathrm{RS}+$ $\mathrm{RR}) \times 100 \%$.

${ }^{3} R R$ frequency $=R R \div(S S+R S+R R) \times 100 \% ;{ }^{4} R$ frequency $=(R R+1 / 2 R S) \div$ $(S S+R S+R R) \times 100 \%$.

The L1035F/S mutation could also be linked with the M943V and I973T mutations because the $P$-values for these combinations are only slightly above 0.05 . And sequencing data confirms the existence of linkage in some mosquitoes.

Correlation between resistance and mutation frequencies The degree and significance of correlation between resistance to deltamethrin and cyhalothrin and the frequency of each mutation is shown in Table 6. The frequency of the L1035F mutation was significantly correlated with resistance to both deltamethrin $\left(\mathrm{R}^{2}=0.536, \mathrm{P}=0.049\right)$ and cyhalothrin $\left(R^{2}=0.626, P=0.030\right)$, and the combined frequency of the L1035F and L1035S mutations was significantly correlated with resistance to deltamethrin $\left(R^{2}=0.661, P=0.025\right)$, and even more significantly correlated with resistance to cyhalothrin $\left(R^{2}=0.803, P=0.008\right)$ (Figures $4,5,6$ and 7). Frequencies of all other mutations were not correlated with either deltamethrin or cyhalothrin resistance. Significant cross-resistance between the two insecticides was also detected $\left(R^{2}=0.930, P<0.01\right)$ (Figure 8).

\section{Discussion}

Insecticides have been used to control mosquitoes for more than half a century. Their indiscriminate use has, however, resulted in high levels of insecticide resistance in many mosquito species [8-10]. We tested the resistance of six Chinese $C x$. p. quinquefasciatus populations to deltamethrin and cyhalothrin. Our results show that, compared to a susceptible laboratory strain, these six populations displayed a 9- to 1019-fold resistance to deltamethrin, and a 14- to 1291-fold resistance to cyhalothrin. The high resistance of the $\mathrm{FH}$ population may be related to its breeding habitat. This population frequently breeds in pools of water in peasant courtyards that are often polluted by insecticides.

The frequent use of insecticides has created an intense selection pressure for traits that confer resistance to them, such as changes in behavior, epidermal structure, metabolic enzymes and target-site mutations. Resistance may be conferred by the development of one, or more, of these traits. Osta et al. found that the dramatic reduction in the 
Table 4 P-value of HWE test for heterozygote deficiency and excess confirmed at six loci in six Cx. p. quinquefasciatus populations

\begin{tabular}{|c|c|c|c|c|c|c|c|c|c|c|c|c|c|}
\hline \multirow{2}{*}{ Mutations } & \multicolumn{2}{|c|}{$\mathrm{FH}$} & \multicolumn{2}{|c|}{ PX } & \multicolumn{2}{|c|}{$\mathrm{BA}$} & \multicolumn{2}{|c|}{ ZJ } & \multicolumn{2}{|c|}{$\mathrm{CL}$} & \multicolumn{2}{|c|}{ LS } & \multirow{2}{*}{$\begin{array}{c}\text { All populations } \\
\text { P-value }\end{array}$} \\
\hline & Def. & Exc. & Def. & Exc. & Def. & Exc. & Def. & Exc. & Def. & Exc. & Def. & Exc. & \\
\hline V250M & 0.6638 & 0.8045 & 0.8784 & 0.3797 & 0.5647 & 0.8103 & 1.0000 & 0.0729 & 1.0000 & 0.7097 & 0.0144 & 0.9992 & 0.3499 \\
\hline R436K & 1.0000 & 0.0018 & 1.0000 & 0.0018 & 1.0000 & 0.0115 & 1.0000 & 0.0000 & 1.0000 & 0.0008 & 1.0000 & 0.0017 & $<0.01$ \\
\hline M943V & 1.0000 & 0.0060 & 1.0000 & 0.0218 & 1.0000 & 0.0047 & 1.0000 & 0.0611 & 1.0000 & 0.0020 & 1.0000 & 0.0001 & $<0.01$ \\
\hline 1973T & 1.0000 & 0.0523 & 1.0000 & 0.0218 & 1.0000 & 0.0026 & 1.0000 & 0.0904 & 1.0000 & 0.0175 & 1.0000 & 0.0050 & $<0.01$ \\
\hline L1035F/S & 0.4900 & 0.5000 & 0.4186 & 0.5748 & 0.5859 & 0.4458 & 0.9620 & 0.0349 & 0.9990 & 0.0012 & 0.2784 & 0.7220 & $<0.01$ \\
\hline E1901D & 1.0000 & 0.0553 & 0.9902 & 0.0881 & 1.0000 & 0.3579 & 1.0000 & 0.8282 & 1.0000 & 0.2919 & 0.4961 & 0.7498 & 0.3615 \\
\hline
\end{tabular}

frequency of the G119S mutation in Cx pipiens mosquitoes was probably due to the increased use of pyrethroids over organosphosphate insecticides [35]. Therefore, alternating between different kinds of insecticide is one way of reducing the development of resistance to any one type.

We identified seven point mutations at six loci and eleven alternative splices in the sodium channel gene of Chinese Cx. p. quinquefasciatus. The Hardy-Weinberg equilibrium (HWE) describes the theoretical frequency of two alleles at the same locus, in the absence of mutation and selection, in an indefinitely large population with discrete generations after one generation of random mating [36]. The results of HWE tests suggested that mutations at four of these six loci significantly deviated from the HWE $(\mathrm{P}<0.05)$. Among these, the $\mathrm{R} 436 \mathrm{~K}$ mutation occurred at a frequency of nearly $50 \%$ in all six populations and there was an excess of heterozygotes with this mutation $(\mathrm{P}<0.05)$. How this mutation

Table 5 Chi-squared test results showed linkage between pairs of loci across six populations of $C x$. $p$. quinquefasciatus (Fisher's method)

\begin{tabular}{llll}
\hline Locus pair & X2 & df & P-value \\
\hline V250M \& R436K & 0.0000 & 2 & 1.0000 \\
V250M \& M943V & 10.307 & 12 & 0.5890 \\
R436K \& M943V & 0.0000 & 2 & 1.0000 \\
V250M \& 1973T & 13.680 & 12 & 0.3216 \\
R436K \& 1973T & 0.0000 & 2 & 1.0000 \\
M943V \& 1973T & Infinity & 12 & $<0.01$ \\
V250M \& L1035F/S & 13.758 & 12 & 0.3164 \\
R436K \& L1035F/S & 1.1216 & 2 & 0.5707 \\
M943V \& L1035F/S & 20.486 & 12 & 0.0584 \\
I973T \& L1035F/S & 20.864 & 12 & 0.0524 \\
V250M \& E1901D & 12.551 & 12 & 0.4025 \\
R436K \& E1901D & 0.0000 & 2 & 1.0000 \\
M943V \& E1901D & 8.3050 & 12 & 0.7609 \\
I973T \& E1901D & 6.0710 & 12 & 6.0710 \\
L1035F/S \& E1901D & 16.813 & 12 & 0.1568 \\
\hline
\end{tabular}

developed and its role, if any, in pesticide resistance requires further investigation.

Mutations at three other loci (M943, I973 and L1035) also deviated from the HWE, and some populations had an excess of heterozygotes with these mutations. L1014 (L1035 according to our sequencing) is a classical mutation associated with the use of pyrethroid insecticides. One reason why the previous three mutations deviate from the HWE may be because a long period of selection has led to them becoming fixed. Mutations at two other loci (V250M and E1901D) did not deviate from the HWE.

We found evidence of significant linkage between the M943V and I973T mutations $(\mathrm{P}<0.01)$ and $P$-values for a Chi-squared test of association between L1014F/S and M943V and I973T were also only slightly above 0.05. Our sequencing data support linkage between

Table 6 Correlations calculated between frequencies of sodium channel gene mutations in $C x$. p. quinquefasciatus and resistance to deltamethrin and cyhalothrin

\begin{tabular}{ccccc}
\hline Mutations & Insecticide & $\mathbf{R}(\mathbf{9 5} \% \mathbf{C L})$ & $\mathbf{R}^{\mathbf{2}}$ & $\begin{array}{c}\boldsymbol{P} \text {-value } \\
(\mathbf{a}=\mathbf{0 . 0 5})\end{array}$ \\
\hline V250M & deltamethrin & $0.054(-0.793,0.829)$ & 0.003 & 0.460 \\
M973V & cyhalothrin & $-0.046(-0.827,0.795)$ & 0.002 & 0.465 \\
& deltamethrin & $0.022(-0.804,0.819)$ & 0.001 & 0.483 \\
1973T & cyhalothrin & $0.235(-0.713,0.879)$ & 0.055 & 0.327 \\
& deltamethrin & $-0.240(-0.880,0.710)$ & 0.058 & 0.323 \\
L1035F & cyhalothrin & $-0.158(-0.859,0.750)$ & 0.025 & 0.383 \\
& deltamethrin & $0.732(-0.197,0.968)$ & 0.536 & 0.049 \\
L1035S & cyhalothrin & $0.791(-0.057,0.976)$ & 0.626 & 0.030 \\
& deltamethrin & $0.007(-0.809,0.814)$ & 0.000 & 0.495 \\
L1035F + & cyhalothrin & $0.040(-0.797,0.825)$ & 0.002 & 0.470 \\
L1035S & deltamethrin & $0.813(0.005,0.979)$ & 0.661 & 0.025 \\
& & & & \\
E1901D & cyhalothrin & $0.896(0.309,0.989)$ & 0.803 & 0.008 \\
& deltamethrin & $0.609(-0.401,0.951)$ & 0.371 & 0.100 \\
\hline CL= confidence limits. & & & &
\end{tabular}




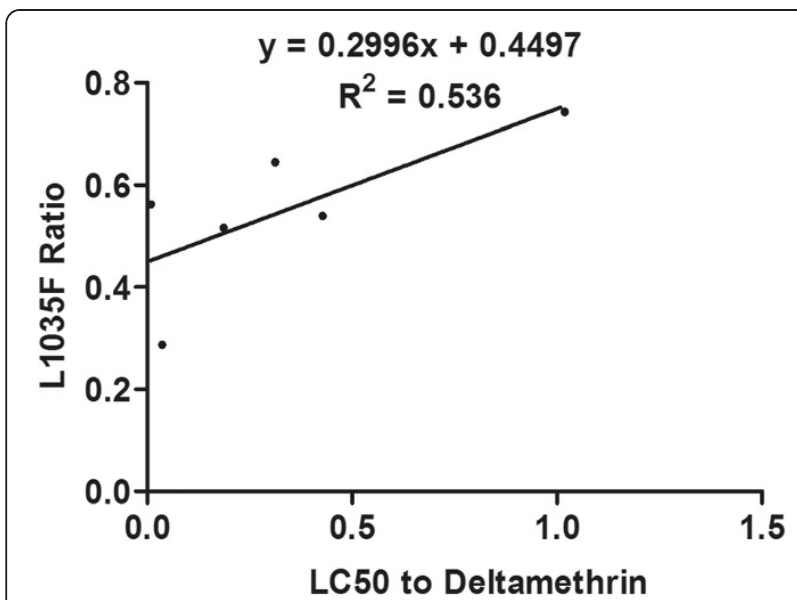

Figure 4 Linear regression of the relationship between the frequency of the L1035F mutation and deltamethrin resistance.

these mutations in some mosquitoes but this requires further confirmation.

The V250M mutation is the first to be discovered in the $C x . p$. quinquefasciatus sodium channel gene's IS4 domain, in which mutations rarely occur. The frequency of this mutation was not correlated with resistance to either deltamethrin or cyhalothrin so further research is required to determine its function, if any, in pesticide resistance.

Our results provide the first confirmation of the R436K mutation, located between the first and second homology domains of the sodium channel gene near the IS6 domain, in $C x . p$. quinquefasciatus. The E434K mutation was first identified near the IS6 domain of the sodium channel gene in the German cockroach. This mutation is associated with two other mutations, C764R and L993F (L1014F), that are closely linked to resistance to the pyrethroid insecticide cypermethrin [37]. We did not find any correlation between the frequency of this mutation and pyrethroid

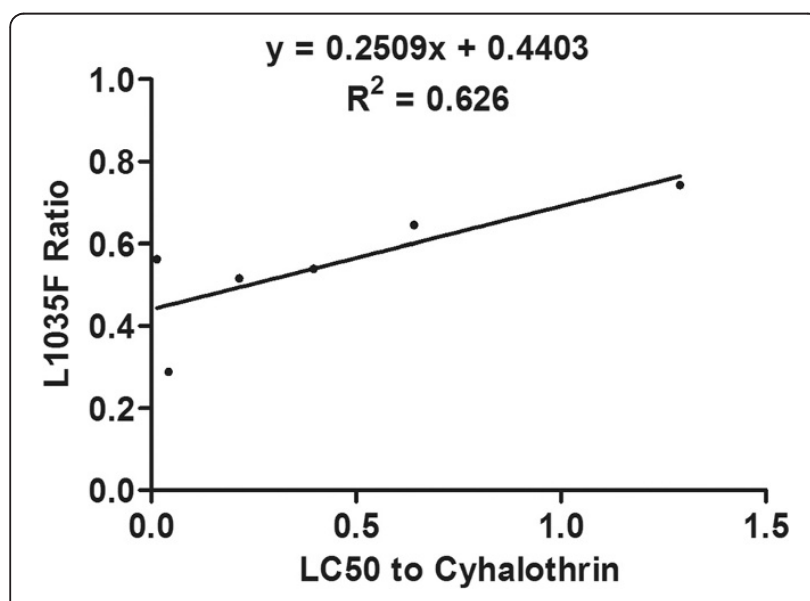

Figure 5 Linear regression of the relationship between the frequency of the L1035F mutation and cyhalothrin resistance.

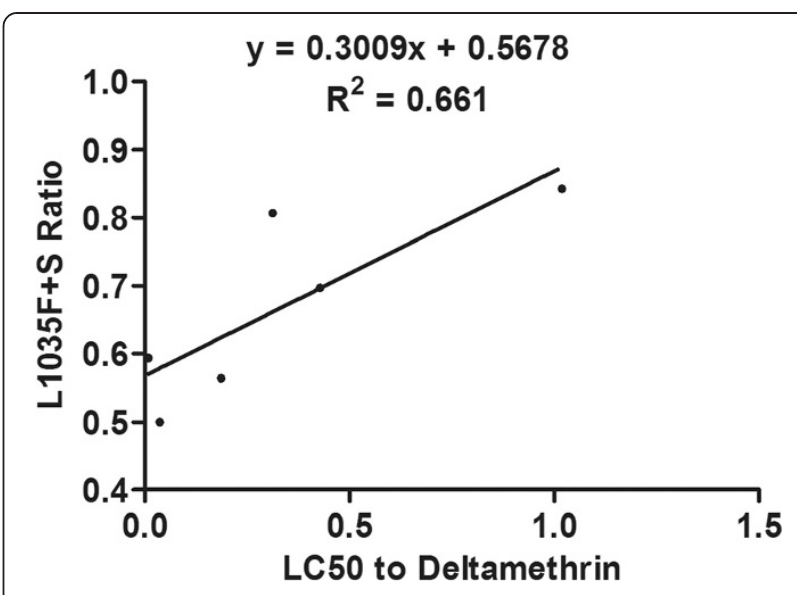

Figure 6 Linear regression of the relationship between the frequency of the L1035 F+S mutation and deltamethrin resistance.

resistance. However, almost all individuals with this mutation were heterozygotes and its frequency was almost $50 \%$ across all populations. The reasons for its prevalence require further investigation.

The M943V and I973T mutations are located at the junctions between IIS4 and IIS5, and between IIS5 and IIS6, in the sodium channel gene and were significantly linked $(\mathrm{P}<0.01)$. The M943V mutation is only three amino acids from the M918T site (the amino acid number in the housefly sodium channel gene, GenBank Accession No.: X96668). The M918T mutation is usually associated with the L1014F mutation in which case it confers "super-kdr" resistance. However, some studies have reported super-kdr resistance in the absence of the L1014F mutation. For example, Benjamin et al. found that the M918T mutation greatly increased the resistance of Tetranychus evansi to pyrethroid insecticides in the absence of the L1014F mutation [38].

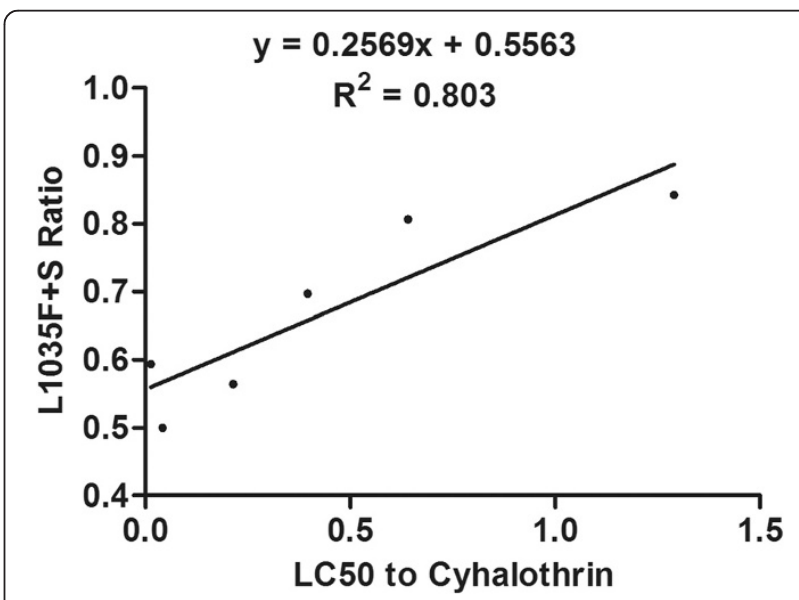

Figure 7 Linear regression of the relationship between the frequency of the $\mathrm{L} 1035 \mathrm{~F}+\mathrm{S}$ mutation and cyhalothrin resistance. 


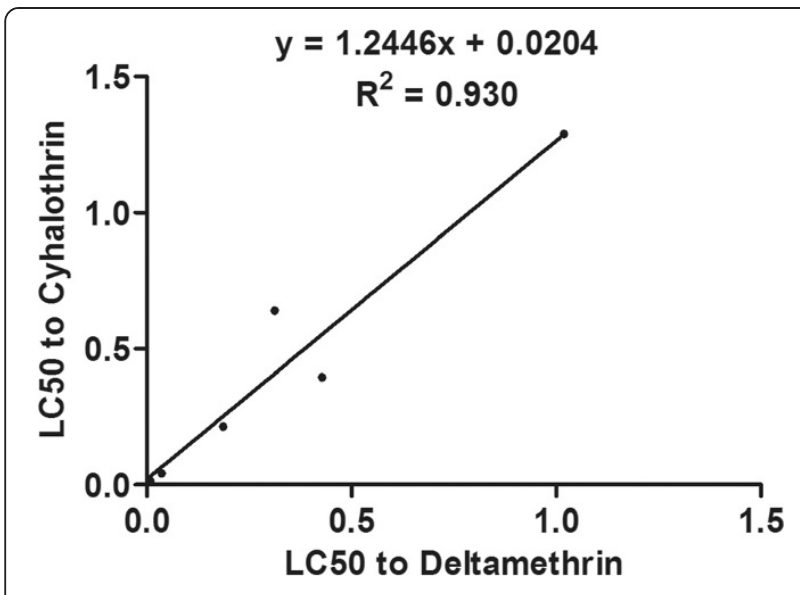

Figure 8 Linear regression of the relationship between deltamethrin and cyhalothrin resistance $\left(\mathrm{LC}_{50}\right)$ in $\mathrm{CX}_{\mathrm{.}}$. p. quinquefasciatus.

The I874M mutation (corresponding to the M918 position in the housefly) in mammals can result in a 100-fold desensitization of the sodium channel [39]. Another study identified a methionine to valine replacement at this position in the Bemisia tabaci para-sodium channel gene that was unrelated to resistance [40]. We also detected a methionine to valine replacement at the fourth amino acid after the M918 position in all six Cx. p. quinquefasciatus populations that was not correlated with deltamethrin or cyhalothrin resistance. How this mutation arose, its connection with the M918 point mutation, linkage with the I973T mutation and role, if any, in resistance, requires further investigation.

L1035 is the site of the classic knockdown resistance mutation L1014 (amino acid number in the housefly sodium channel gene, GenBank Accession No.: X96668). It is located in the IIS6 domain of sodium channel, and has been relatively well researched. Subsequent studies have identified mutations associated with knockdown resistance in a variety of insects, for example, Aphis gossypii [15], the German cockroach [16], Myzus persicae [17] Triatoma infestans [21], Anopheles gambiae, Anopheles stephensi and Anopheles arabiensis [22]. In addition, recent studies have that the L1014S mutation is associated with permethrin, cypermethrin, cyhalothrin and DDT resistance in Anopheles sinensis, An. vagus and $A n$. peditaeniatus, [41]; with deltamethrin resistance in $C x$ p. pallens [42], and with permethrin and DDT resistance in Anopheles gambiae [13,43].

Another study found a new mutation, V1010L, that is closely linked to the L1014S mutation in Anopheles culicifacies but did not mention if it was associated with resistance [25]. As previously mentioned, the co-occurrence of the L1014F and M918T mutations can lead to super-kdr resistance in many insects. For example, these two mutations are closely related to cyhalothrin and permethrin resistance in Haematobia irritans [29]; and resistance to a suite (permethrin, bifenthrin, tefluthrin, deltamethrin, cypermethrin, cyhalothrin and fluvalinate) of pyrethoid insecticides in Myzus persicae [30]. No one has so far, however, detected super-kdr resistance in a mosquito species.

In Drosophila melanogaster, the L1014F, M918T and T929I mutations affect the sodium channel currents in the presence of deltamethrin and permethrin, suggesting that these mutations confer resistance to those pesticides [44]. Other authors have found the above three mutations in the sodium channel gene of pyrethroid-resistant Thrips tabaci [45] and identified the L1014H, L1014C and L1014W mutations [26-28,46,47].

Studies have showed mutations in L1014 could lead to a reduction in susceptibility to a variety of pyrethroids and a decay of tail current. And then lead to develop resistance $[48,49]$. We found that the L1035F and L1035S mutations were present in all six $C x$. $p$. quinquefasciatus populations we sampled and that these mutations were significantly correlated with deltamethrin and cyhalothrin resistance. This may be related to the frequent use of these pesticides at our sampling sites. In addition, we found that the frequency of the leucine to serine replacement in all six populations was lower than that of the L1035F mutation. The combined frequency of the L1035F and S mutations was highly correlated with resistance, especially cyhalothrin resistance $\left(R^{2}=0.803, P<0.01\right)$, which suggests that mosquitoes in the sampled populations have developed additional mutations except the L1035F mutation in response to strong selection pressure.

This study was the first to detect the E1901D mutation, located on the sodium channel C-terminal tail, in $C x$. p. quinquefasciatus. There has, so far, been relatively little research on this fragment but it appears to be unrelated to deltamethrin and cyhalothrin resistance. Determining the function of such mutations will require further study.

We confirmed eleven alternative splices in the sodium channel gene of $C x . p$. quinquefasciatus. These reflect dynamic change and higher level reassembly of genetic information that can greatly increase the richness of the coding sequence without changing genomic DNA [50]. Liu et al. (2012) found thirteen different sodium channel variants in $C x . p$. quinquefasciatus and demonstrated that this alternative splicing was related to pyrethroid resistance [51]. The eleven alternative splices we found differed from those found by Liu et al. They may have some significance in the rich diversity of the sodium channel protein, but further research is required to determine their role, if any, in pyrethroid resistance.

\section{Conclusion}

In the study, seven amino acid alterations were found (V250M, R436K, M943V, I973T, L1035F, L1035S 
and E1901D) in the sodium channel gene of $C x . p$. quinquefasciatus from six field populations in China. Among them, the L1035F and L1035S mutations' frequencies were associated with resistance to deltamethrin and cyhalothrin. And the M943V and I973T mutations were significant linkage with each other in the sodium channel gene. Identifying these mutations may be of practical benefit to the development of pesticide resistance management programs.

\section{Competing interests}

The authors declare that they have no competing interests.

\section{Authors' contribution}

$\mathrm{MHZ}$ carried out the molecular genetic studies, participated in the sequence alignment and drafted the manuscript. The experiments conceived and designed by MHZ CXL YDD XXG YMZ DX TYZ, performed the experiments by MHZ XR ZMW TY XJZ JXS WJH. The data analyzed by MHZ CXL GW HDZ. All authors read and approved the final manuscript.

\section{Acknowledgments}

This work was funded by grants from the Infective Diseases Prevention and Cure Project of China (No.2008ZX10004 and No.2012ZX10004219).

\section{Author details}

'Beijing Institute of Microbiology and Epidemiology, State Key Laboratory of Pathogen and Biosecurity, Beijing, China. ${ }^{2}$ Anhui Medical University, Hefei, China.

Received: 30 May 2014 Accepted: 1 August 2014

Published: 15 August 2014

\section{References}

1. WHO: Geographical Distribution of Arthropod-Borne Diseases and their Principal Vectors. 1989.

2. Kwan JL, Kluh S, Madon MB, Reisen WK: West Nile virus emergence and persistence in Los Angeles, California, 2003-2008. Am J Trop Med Hyg 2010, 83(2):400.

3. Savage HM, Smith GC, Moore CG, Mitchell CJ, Townsend M, Marfin AA: Entomologic investigations of an epidemic of St. Louis encephalitis in Pine Bluff, Arkansas, 1991. Am J Trop Med Hyg 1993, 49(1):38-45.

4. Turell MJ, Linthicum KJ, Patrican LA, Davies FG, Kairo A, Bailey CL: Vector competence of selected African mosquito (Diptera: Culicidae) species for Rift Valley fever virus. J Med Entomol 2008, 45(1):102-108.

5. Sang R, Kioko E, Lutomiah J, Warigia M, Ochieng C, O'Guinn M, Lee JS, Koka H, Godsey M, Hoel D: Rift Valley fever virus epidemic in Kenya, 2006/2007: the entomologic investigations. Am J Trop Med Hyg 2010, 83(2):28.

6. Narahashi T: Molecular and cellular approaches to neurotoxicology: past, present and future. Neurotox 1988, 88:563-582.

7. Kawada H, Dida GO, Ohashi K, Komagata O, Kasai S, Tomita T, Sonye G, Maekawa Y, Mwatele C, Njenga SM: Multimodal pyrethroid resistance in malaria vectors, Anopheles gambiae ss, Anopheles arabiensis, and Anopheles funestus ss in western Kenya. PLoS One 2011, 6(8):e22574.

8. Jones CM, Machin C, Mohammed K, Majambere S, Ali AS, Khatib BO, Mcha J, Ranson $\mathrm{H}$, Kelly-Hope LA: Insecticide resistance in Culex quinquefasciatus from Zanzibar: implications for vector control programmes. Parasit Vectors 2012, 5:78.

9. Akiner M, Simsek F, Caglar S: Insecticide resistance of Culex pipiens (Diptera: Culicidae) in Turkey. J Pestic Sci 2009, 34:4.

10. Balkew M, Ibrahim M, Koekemoer LL, Brooke BD, Engers H, Aseffa A, Gebre-Michael T, Elhassen I: Research Insecticide resistance in Anopheles arabiensis (Diptera: Culicidae) from villages in central, northern and south west Ethiopia and detection of kdr mutation. Parasit Vectors 2010, 3:40.

11. Sarkar M, Bhattacharyya IK, Borkotoki A, Baruah I, Srivastava RB: Development of physiological resistance and its stage specificity in Culex quinquefasciatus after selection with deltamethrin in Assam. India Memórias do Instituto Oswaldo Cruz 2009, 104(5):673-677.
12. Chandre F, Darrier F, Manga L, Akogbeto M, Faye O, Mouchet J, Guillet P. Status of pyrethroid resistance in Anopheles gambiae sensu lato. Bull World Health Organ 1999, 77(3):230-234.

13. Ranson H, Jensen B, Vulule J, Wang X, Hemingway J, Collins F: Identification of a point mutation in the voltage-gated sodium channel gene of Kenyan Anopheles gambiae associated with resistance to DDT and pyrethroids. Insect Mol Biol 2000, 9(5):491-497.

14. Dong K: Insect sodium channels and insecticide resistance. Invert Neurosci 2007, 7(1):17-30

15. Marshall KL, Moran C, Chen Y, Herron GA: Detection of kdr pyrethroid resistance in the cotton aphid, Aphis gossypii (Hemiptera: Aphididae), using a PCR-RFLP assay. J Pestic Sci 2012, 37:2.

16. Dong $K$ : A single amino acid change in the para sodium channel protein is associated with knockdown-resistance ( $\mathrm{kdr}$ ) to pyrethroid insecticides in German cockroach. Insect Biochem Mol Biol 1997, 27(2):93-100.

17. Martinez-Torres D, Foster S, Field L, Devonshire A, Williamson M: A sodium channel point mutation is associated with resistance to DDT and pyrethroid insecticides in the peach-potato aphid, Myzus persicae (Sulzer) (Hemiptera: Aphididae). Insect Mol Biol 1999, 8(3):339-346.

18. Brun-Barale A, Bouvier JC, Pauron D, Bergé JB, Sauphanor B: Involvement of a sodium channel mutation in pyrethroid resistance in Cydia pomonella $\mathrm{L}$, and development of a diagnostic test. Pest Manag SCi 2005, 61(6):549-554

19. Forcioli D, Frey B, Frey J: High nucleotide diversity in the para-like voltage-sensitive sodium channel gene sequence in the western flower thrips (Thysanoptera: Thripidae). J Econ Entomol 2002, 95(4):838-848.

20. Nauen R, Zimmer CT, Andrews M, Slater R, Bass C, Ekbom B, Gustafsson G, Hansen LM, Kristensen M, Zebitz CP: Target-site resistance to pyrethroids in European populations of pollen beetle, Meligethes aeneus F. Pestic Biochem Phys 2012, 103(3):173-180.

21. Fabro J, Sterkel M, Capriotti N, Mougabure-Cueto G, Germano M, Rivera-Pomar R, Ons S: Identification of a point mutation associated with pyrethroid resistance in the para-type sodium channel of Triatoma infestans, a vector of Chagas' disease. Infect Genet Evol 2012, 12(2):487-491.

22. Yewhalaw D, Wassie F, Steurbaut W, Spanoghe P, Van Bortel W, Denis L, Tessema DA, Getachew Y, Coosemans M, Duchateau L: Multiple insecticide resistance: an impediment to insecticide-based malaria vector control program. PLoS One 2011, 6(1):e16066.

23. Busvine J: Mechanism of resistance to insecticide in houseflies. Nature 1951, 168:193-195.

24. Milani R: Mendelian behavior of resistance to the knock-down action of DDT and correlation between knock-down and mortality in Musca domestica L. Rendiconti-Istituto Superiore di Sanita 1955, 19(11):1107-1143.

25. Singh OP, Dykes CL, Das MK, Pradhan S, Bhatt RM, Agrawal OP, Adak T: Research Presence of two alternative kdr-like mutations, L1014F and L1014S, and a novel mutation, V1010L, in the voltage gated $\mathrm{Na}+$ channel of Anopheles culicifacies from Orissa. India Malaria J 2010, 9:146.

26. Liu N, Pridgeon JW: Metabolic detoxication and the kdr mutation in pyrethroid resistant house flies, Musca domestica (L.). Pestic Biochem Phys 2002, 73(3):157-163.

27. Tan $W L$, Li CX, Wang ZM, Liu MD, Dong YD, Feng XY, Wu ZM, Guo XX, Xing D, Zhang YM: First Detection of Multiple Knockdown Resistance (kdr)-Like Mutations in Voltage-Gated Sodium Channel Using Three New Genotyping Methods in Anopheles sinensis From Guangxi Province, China. J Med Entomol 2012, 49(5):1012-1020.

28. WANG ZM LICX, Xing D, YU YH, Liu N, XUE RD DONGYD, ZHAO TY: Detection and widespread distribution of sodium channel alleles characteristic of insecticide resistance in Culex pipiens complex mosquitoes in China. Med Vet Entomol 2012, 26(2):228-232.

29. Guerrero FD, Jamroz RC, Kammlah D, Kunz SE: Toxicological and molecular characterization of pyrethroid-resistant horn flies, Haematobia irritans: identification of $k d r$ and super-kdr point mutations. Insect Biochem Molec 1997, 27(8):745-755.

30. Eleftherianos I, Foster S, Williamson M, Denholm I: Characterization of the M918T sodium channel gene mutation associated with strong resistance to pyrethroid insecticides in the peach-potato aphid, Myzus persicae (Sulzer). Bull Entomol Res 2008, 98(02):183-191.

31. Williamson MS, Martinez-Torres D, Hick CA, Devonshire AL: Identification of mutations in the houseflypara-type sodium channel gene associated with knockdown resistance (kdr) to pyrethroid insecticides. Mol Gen Genet 1996, 252(1-2):51-60. 
32. Cetin H, Yanikoglu A, Cilek JE: Evaluation of the naturally-derived insecticide spinosad against Culex pipiens L.(Diptera: Culicidae) larvae in septic tank water in Antalya, Turkey. J Vector Ecol 2005, 30(1):151-154.

33. Zhao MH, Ran X, Dong YD, Guo XX, Zhang YM, Xing D, Wu ZM, Li CX, Zhao TY: Clone and Sequencing of Sodium Channel Gene from Field Culex Pipiens Pallens. Acta Parasitologica Et Medica Entomologica Sinica 2014, 21(1):17-22.

34. Li CX, Dong YD, Song FL, Zhang XL, Zhao TY: An amino acid substitution on the acetylcholinesterase in the field strains of house mosquito, Culex pipiens pallens (Diptera: Culicidae) in China. Entomol News 2009, 120(5):464-475.

35. Osta MA, Rizk ZJ, Labbé P, Weill M, Knio K: Insecticide resistance to organophosphates in Culex pipiens complex from Lebanon. Parasit Vectors 2012, 5(1):1-6.

36. Mayo O: A century of Hardy-Weinberg equilibrium. Twin Res Hum Genet 2008, 11(03):249-256.

37. Liu Z, Valles SM, Dong K: Novel point mutations in the German cockroach para sodium channel gene are associated with knockdown resistance (kdr) to pyrethroid insecticides. Insect Biochem Molec 2000, 30(10):991-997.

38. Nyoni BN, Gorman K, Mzilahowa T, Williamson MS, Navajas M, Field LM, Bass C: Pyrethroid resistance in the tomato red spider mite, Tetranychus evansi, is associated with mutation of the para-type sodium channel. Pest Manag Sci 2011, 67(8):891-897.

39. Vais $H$, Atkinson S, Eldursi N, Devonshire A, Williamson M, Usherwood P: A single amino acid change makes a rat neuronal sodium channel highly sensitive to pyrethroid insecticides. FEBS Lett 2000, 470(2):135-138.

40. Morin S, Williamson M, Goodson S, Brown J, Tabashnik B, Dennehy T: Mutations in the Bemisia tabaci para sodium channel gene associated with resistance to a pyrethroid plus organophosphate mixture. Insect Biochem Molec 2002, 32(12):1781-1791.

41. Verhaeghen K, Van Bortel W, Trung HD, Sochantha T, Keokenchanh K, Coosemans M: Knockdown resistance in Anopheles vagus, An. sinensis, An. paraliae and An. peditaeniatus populations of the Mekong region. Parasit Vectors 2010, 3(1):59.

42. Chen L, Zhong D, Zhang D, Shi L, Zhou G, Gong M, Zhou H, Sun Y, Ma L, He J: Molecular ecology of pyrethroid knockdown resistance in Culex pipiens pallens mosquitoes. PLoS One 2010, 5(7):e11681.

43. Stump AD, Atieli FK, Vulule JM, Besansky NJ: Dynamics of the pyrethroid knockdown resistance allele in western Kenyan populations of Anopheles gambiae in response to insecticide-treated bed net trials. Am J Trop Med Hyg 2004, 70(6):591-596.

44. Vais H, Atkinson S, Pluteanu F, Goodson S, Devonshire A, Williamson M, Usherwood P: Mutations of the para sodium channel of Drosophila melanogaster identify putative binding sites for pyrethroids. Mol Pharmacol 2003, 64(4):914-922.

45. Toda S, Morishita M: Identification of three point mutations on the sodium channel gene in pyrethroid-resistant Thrips tabaci (Thysanoptera: Thripidae). J Econ Entomol 2009, 102(6):2296-2300.

46. Park Y, Taylor MF: A novel mutation $\mathrm{L} 1029 \mathrm{H}$ in sodium channel gene hscp associated with pyrethroid resistance for Heliothis virescens (Lepidoptera: Noctuidae). Insect Biochem Molec 1997, 27(1):9-13.

47. Kim H, Baek JH, Lee W-J, Lee SH: Frequency detection of pyrethroid resistance allele inAnopheles sinensis populations by real-time PCR amplification of specific allele (rtPASA). Pestic Biochem Phys 2007, 87(1):54-61.

48. Smith TJ, Lee SH, Ingles PJ, Knipple DC, Soderlund DM: The L1014F point mutation in the house fly Vssc1 sodium channel confers knockdown resistance to pyrethroids. Insect Biochem Mol Biol 1997, 27(10):807-812.

49. Vais H, Williamson MS, Goodson SJ, Devonshire AL, Warmke JW, Usherwood PN, Cohen CJ: Activation of Drosophila sodium channels promotes modification by deltamethrin. Reductions in affinity caused by knock-down resistance mutations. J Gen Physio/ 2000, 115(3):305-318.

50. Blencowe BJ: Alternative splicing: new insights from global analyses. Cell 2006, 126(1):37-47

51. He L, Li T, Zhang L, Liu N: Multiple sodium channel variants in the mosquito Culex quinquefasciatus. Int J Bio/ Sci 2012, 8(10):1291.

\section{doi:10.1186/1756-3305-7-369}

Cite this article as: Zhao et al.: Sodium channel point mutations associated with pyrethroid resistance in Chinese strains of Culex pipiens quinquefasciatus (Diptera: Culicidae). Parasites \& Vectors 2014 7:369.

\section{Submit your next manuscript to BioMed Central and take full advantage of:}

- Convenient online submission

- Thorough peer review

- No space constraints or color figure charges

- Immediate publication on acceptance

- Inclusion in PubMed, CAS, Scopus and Google Scholar

- Research which is freely available for redistribution 